\title{
Editorial
}

\section{Advances in Alzheimer's disease (AAD): Standing firm at its first anniversary}

\author{
Xiao-Xin Yan \\ Department of Anatomy and Neurobiology, Central South University Xiangya School of Medicine, Changsha, China; \\ Corresponding Author: yanxiaoxin@csu.edu.cn
}

Received 22 April 2013; revised 24 May 2013; accepted 2 June 2013

Copyright (C) 2013 Xiao-Xin Yan. This is an open access article distributed under the Creative Commons Attribution License, which permits unrestricted use, distribution, and reproduction in any medium, provided the original work is properly cited.

Advances in Alzheimer's Disease (AAD) is an international journal launched last year, dedicated to promote basic, translational and clinical research on Alzheimer's Disease (AD) and brain aging

(http://www.scirp.org/journal/aad/). On its first anniversary, the journal has made substantial achievements and shows a great promise for its future. AAD published the first issue on June 26 last year, followed by the second and third issues in September and December. The first issue of this year was published in March as scheduled. The current issue publishes 3 original and review articles. The published papers were contributed by investigators over the world, mostly outside China, covering broad and diverse topics on $\mathrm{AD}$, from mechanistic study to disease diagnosis, care and treatment. These papers have attracted considerable attention in the field, with total views near 40 thousand and full article downloads over 6 thousand to date.

$\mathrm{AD}$ is the most common type of dementia in the elderly. It attacks individuals aged over 65 in most cases, at a prevalence around $5 \%$, which doubles every decade as the age goes further up. In 2013, an estimated 5 million Americans aged 65 and older have AD. The advances in modern medicine and the improvement in social and envi ronmental conditions will further increase human lifeexpectancy in the coming years, so do for the number of people who will develop this neurodegenerative disease. It is projected that 14 million Americans will live with AD by 2050

(http://www.alz.org/alzheimers disease_facts_and_figur es.asp?type=alzchptfooter) [1,2]. The situation in China is perhaps even worse and more alarming because of its population in the world, which is rapidly aging. While there is little official epidemiological record, China may already have more than 6 - 8 million AD patients today. What's more, the overall life-expectancy for Chinese is now about 76 years

(http://en.wikipedia.org/wiki/List_of_countries_by_life expectancy), but it will catch up the current mid-80s records in most western/developed countries within 10 years or so. Together with other problems and difficulties (e.g., the one-child policy), China may soon face one of the greatest socioeconomic and healthcare challenges in her journey to modernization

(http://charls.ccer.edu.cn).

$\mathrm{AD}$ is pathologically characterized by amyloid plaques, neurofibrillary tangles, neuritic pathology, gliosis, and neuronal and synaptic loss in vulnerable brain regions especially in the limbic and neocortical areas [3-5]. Aging is the greatest risk factor, while vascular and metabolic deficits, trauma, inflammation, environmental insults, genetic predisposition, and physiological "wasting" of cognitive and physical reserve are also potential etiological factors. Many theories have been proposed for the pathogenesis of this disease. Among all, the amyloid hypothesis emphasizes accumulation of $\beta$-amyloid peptides $(\mathrm{A} \beta)$ being the leading pathogenic factor. The mitochondria/metabolic stress cascade hypothesis considers age-inherent metabolic failure or oxidative damages to mitochondrial DNA, RNA, lipid and protein as the primary pathogenic mechanism. The cognitive reserve hypothesis suggests that reduced brain use plays an important role in dementia and AD development. The calcium hypothesis posits $\mathrm{Ca}^{2+}$ homeostatic deregulation contributing to neuronal death and functional decline in brain aging and AD [5-9]. Evidence exists in supporting each of these hypotheses, reflecting the nature of complexity and multi-dimensional abnormalities of this disease. At present, efforts are particularly needed to identify the fundamental molecular/cellular mechanism that may unify the risk factors, pathological manifestations and functional loss in this disease [8,9]. Because there are no 
available treatments, joint efforts at governmental, academic, clinical and industrial levels are urgently needed to fight against $\mathrm{AD}$ across the globe [10].

AAD is one of the journals sponsored by the Scientific Research Publishing group headquartered in Wuhan, China. It is the first, and in fact, currently the only specialty journal in the AD field in China. It was launched under the philosophy of free share and use of scientific information. This open-access online journal has a world-wide representative panel of editorial board members, who, together with external reviewers, carry out vigorous and fair evaluation on each submitted manuscript. AAD charges a very affordable publication fee for accepted papers, and manuscripts in all aspects of AD are considered for publication. This journal is currently indexed by a number of world-class databases/searching engines including CrossRef and Google Scholar

(http://www.scirp.org/journal/aad/). Besides its internet accessibility, AAD is now broadly distributed via the library system among universities in mainland China as well as many institutions over the world.

The editorial team and publisher are greatly encouraged by the achievements through the first year of operation, and we expect a healthy growth of this journal in the future. As a part of global effort in combating neurodegenerative diseases and improving human life in the world, AAD seeks to serve a unique and important international platform for scientific communication in $\mathrm{AD}$ research, prevention and therapy.

\section{REFERENCES}

[1] Hampel, H., Prvulovic, D., Teipel, S., Jessen, F., Luckhaus, C., Frolich, L., Riepe, M.W., Dodel, R., Leyhe, T., Bertram, L., Hoffmann, W. and Faltraco, F. (2011) The future of Alzheimer's disease: The next 10 years. Progress in Neurobiology, 95, 718-728. doi:10.1016/j.pneurobio.2011.11.008

[2] Contino, M., Cantore, M., Leopoldo, M. and Colabufo,
N.A. (2013) Biomarkers for the early diagnosis of Alzheimer's disease: The challenge of XXI century. $A d$ vances in Alzheimer's Disease, 1, 13-30. doi:10.4236/aad.2013.21003

[3] Braak, H. and Del Tredici, K. (2012) Where, when, and in what form does sporadic Alzheimer's disease begin? Current Opinion in Neurology, 25, 708-714. doi:10.1097/WCO.0b013e32835a3432

[4] Cai, Y., Xiong, K., Zhang, X.M., Cai, H., Luo, X.G., Feng, J.C., Clough, R.W., Struble, R.G., Patrylo, P.R., Chu, Y., Kordower, J.H. and Yan, X.X. (2010) $\beta$-Secretase-1 elevation in aged monkey and Alzheimer's disease human cerebral cortex occurs around the vasculature in partnership with multisystem axon terminal pathogenesis and $\beta$-amyloid accumulation. European Journal of Neuroscience, 32, 1223-1238. doi:10.1111/j.1460-9568.2010.07376.x

[5] Radak, Z., Hart, N., Sarga, L., Koltai, E., Atalay, M., Ohno, H. and Boldogh, I. (2010) Exercise plays a preventive role against Alzheimer's disease. Journal of Alzheimers Disease, 20, 777-783.

[6] Stern, Y. (2012) Cognitive reserve in ageing and Alzheimer's disease. Lancet Neurology, 11, 1006-1012. doi:10.1016/S1474-4422(12)70191-6

[7] Skaper, S.D. (2012) Alzheimer's disease and amyloid: Culprit or coincidence? International Review of Neurobiology, 102, 277-316. doi:10.1016/B978-0-12-386986-9.00011-9

[8] Swerdlow, R.H. (2012) Alzheimer's disease pathologic cascades: Who comes first, what drives what. Neurotoxicity Research, 22, 182-194. doi:10.1007/s12640-011-9272-9

[9] Marques, S.C., Oliveira. C.R., Outeiro. T.F. and Pereira. C.M. (2010) Alzheimer's disease: The quest to understand complexity. Journal of Alzheimers Disease, 21, 373-383.

[10] Mullane, K. and Williams, M. (2013) Alzheimer's therapeutics: Continued clinical failures question the validity of the amyloid hypothesis-But what lies beyond? Biochemical Pharmacology, 85, 289-305. doi:10.1016/j.bcp.2012.11.014 